Чернышова Оксана Николаевна, Сутягин Владислав Юрьевич, Черкашнев Роман Юрьевич

\title{
ОСНОВНЫЕ АСПЕКТЫ ПРОВЕДЕНИЯ ОЦЕНКИ ПРАВА НА ЗАКЛЮЧЕНИЕ ДОГОВОРОВ АРЕНДЫ ОБЪЕКТОВ НЕДВИЖИМОСТИ, НАХОДЯЩИХСЯ В ГОСУДАРСТВЕННОЙ ИЛИ МУНИЦИПАЛЬНОЙ СОБСТВЕННОСТИ
}

В статье дана трактовка рыночной стоимости права аренды. Дополнены и конкретизированы отдельные критерии оценки права пользования объектом недвижсимости на условиях аренды, проанализирован характер взаимосвязей между стоимостью права аренды актива и рыночной величиной арендной платы за него. Использование в практике оченки предлагаемых определений юридической и экономической составляющей права пользования на условиях аренды позволит правильно формулировать объект оценки и выбирать вернуюо методологию при проведении оценки права на заключение договора аренды объектов недвижимости, находящиисся в государственной или муниципальной собственности.

Ключевые слова: оченка арендной ставки, оценка права аренды, юридическая суцность аренды, экономическая сущность аренды.

Oksana Shernyshova, Vladislav Sutygin, Roman Cherkashnev MAIN ASPECTS OF CARRYING OUT THE EVALUATION

OF THE RIGHT TO CONCLUDE CONTRACTS OF LEASE OF REAL ESTATE OBJECTS UNDER GOVERNMENT OR MUNICIPAL PROPERTY

The interpretation of the leasehold estate market value was given. Several criteria for assessing the right of use of real estate objects under lease terms were added and specified, and the nature of the relationship between the leasehold estate value of an asset and the market value of an asset rent was analyzed. Using in appraisal practice of the formulated definitions and the proved arguments regarding the legal and economic component of the right to use property on lease terms will allow to determine appraisal object correctly and to choose the right methodology, in particular when assessing the right to enter into a lease agreement for real estate objects in state or public ownership.

Key words: lease rate valuation, leasehold estate valuation, the legal essence of lease, the economic essence of lease.

Bведениe / Introduction. Очень часто в практике оценки приравнивают стоимость права аренды к арендной ставке, тем самым используя одну и ту же методологию в рамках расчета их величин. В частности, с такой проблемой оценщики сталкиваются при оценке права на заключение договора аренды объектов недвижимости, находящихся в государственной или муниципальной собственности в размере арендного платежа. Кроме того, нередко в своей практике оценщики сталкиваются с ситуациями, когда органы власти трактуют первый арендный платеж как совокупность платежей за период срока действия арендного соглашения, тем самым заранее «наставляя〉 оценщика на расчет не годовой арендной ставки, а права аренды за соответствующий период. Цель статьи заключается в том, чтобы разграничить понятия арендной ставки, арендного платежа и права аренды, дать подробное описание юридической и экономической составляющих права аренды и арендной ставки в целях правильного формулирования объекта оценки и правильного использования методологии расчета их стоимостей. 
Maтериалы и методы /Materials and methods. В статье проанализирован состав правомочий права собственности и аренды с точки зрения применения этих понятий для формулирования объекта оценки и для выбора методологии оценки, в том числе при определении начальной цены предмета аукциона при продаже «права на заключение договора аренды». Рассмотрены особенности оценки прав владения и пользования, или только пользования на условиях договора аренды.

В процессе исследования использованы общенаучные логические методы

Результаты и обсуждение / Results and discussion

- 1. Анализ правовых норм в оценке стоимости права на заключение договора аренды объектов недвижимости, находящихся в государственной или муниципальной собственности .

Напомним, что у собственника имущества априори есть три правомочия: владение, пользование и распоряжение имуществом. При заключении договора аренды он передает, как правило, два правомочия: пользование и владение, используя свое право распоряжения.

То есть возможность сдавать имущество в аренду - это часть правомочия распоряжения.

В целом в гражданско-правовой науке России сформировалось понимание распоряжения, с одной стороны, как возможности собственника совершать в отношении своей вещи различные юридические действия, которые могут приводить к установлению обременения на вещь, передаче частичных прав титульного собственника, таких как владение и пользование, либо передаче полного пакета прав - в широком смысле, а с другой стороны, это действие, приводящее к прекращению частичных или всех прав у одного собственника и возникновению данного права у другого посредством отчуждения данной вещи - в узком смысле

И здесь под отчуждением необходимо понимать юридические действия, связанные не только с меной, продажей, дарением вещи, но и ее залогом и передачей в аренду, в связи с тем что залог при обращении на него взыскания в отдельных случаях может привести к переходу права соб́ственности от одного субъекта к другому (от залогодателя к залогодержателю), а аренда накладывает обременение на право собственности. Кроме того, арендодатель после сдачи в аренду вещи теряет право пользования ею в определенном объеме. Таким образом, право пользования, если его отчуждение произошло в результате заключения договора аренды, принадлежит арендатору, а сама арендная плата должна рассматриваться в рамках его обязательств, а не прав. Таким образом, передача вещи в аренду является распоряжением в широком смысле.

Право аренды. Данной формулировки в Гражданском кодексе РФ нет; есть право пользования и владения на условиях аренды, состав правомочий, ограничений и прочие условия которого прописаны в договоре аренды. Статья 606 ГК РФ говорит нам о том, что в соответствии с типовым договором аренды арендодатель предоставляет арендатору имущество на условиях оплаты во временное пользование и владение. При этом продукция либо денежные доходы, которые арендатор получает от пользования данной вещью, признаются его собственностью [1].

Таким образом, любой арендатор будет заинтересован платить за право пользования и владения активом арендные платежи, сопоставимые с рыночными либо же ниже рыночных. Последний вариант, кстати, вполне часто выпадает арендатору при аренде имущества, принадлежащего государству или муниципальному образованию, потому как в нормах земельного права на сегодняшний день существует порядок предоставления в аренду данного имущества, можно сказать, на льготных условиях, в отличие от порядка предоставления, который существовал несколько лет назад. К слову сказать, что государство или муниципалитет нередко трактуют данные нормы по-своему, то есть с позиции своих экономических интересов, связанных с аккумулированием доходов в бюджет, а противоречия, существующие в земельном законодательстве, способствуют этому. Промежуточным этапом в данном процессе выступает оценка передаваемого в аренду государственного (муниципального) актива. На этом этапе нередко возникает ситуация, когда заказчик государственного (муниципального) контракта на оценку данного имущества формулирует объект оценки в задании таким образом (в частности такую практику можно наблюдать 
на примере муниципального образования города Тамбова), что методология расчета может привести к расчетным результатам стоимости, сопоставимым с выгодами арендатора от его владения и пользования, но которые он вынужден будет не лично использовать, а заплатить собственнику. Таким образом, оценщик должен внимательно изучить нормативную базу, регламентирующую процедуру передачи государственного и муниципального имущества в аренду; четко разбираться в составе юридических правомочий, передаваемых в рамках данной процедуры; в составе экономических выгод арендатора и арендодателя; и при этом правильно выбрать методологию расчета в рамках оценки для целей передачи в аренду государственного (муниципального имущества). Все это обосновывает актуальность рассматриваемой темы.

Итак, что именно дает оценщику разбор состава правомочий права владения, пользования и распоряжения? Оценщику, следует понимать, что право аренды, включающее такие правомочия арендатора, как пользование и владение или только пользование объектом на условиях аренды, с экономической точки зрения представляет собой выгоды от пользования и владения, и данные выгоды являются собственностью именно арендатора, а не арендодателя. Если, например, нормы земельного и иного законодательства в этой сфере предусматривают отчуждение данного права по цене права аренды, то оцениваем соответственно данное право по соответствующей ему методологии, если по цене арендного платежа - по методике определения рыночно обоснованной величины арендной платы за пользование и владение активом.

Очень часто в практике оценки приравнивают стоимость права аренды к арендной ставке, тем самым используя одну и ту же методологию в рамках расчета их величин. С позиции законодательства получается, что арендная ставка не может являться выгодой арендатора. По существу. арендная ставка - это его затраты. Также на основе вышесказанного о том, что передача имущества в аренду есть осуществление правомочия распоряжения, а не пользования и не владения, является актуальным при формулировании объекта оценки. Определять объект оценки как «право временного пользования и владения, или пользования на условиях аренды» при фактической оценке арендной платы мы не рекомендуем и разберем этот аспект чуть ниже.

При передаче государственного или муниципального имущества в аренду согласно ст. 105 Приказа ФАС России от 10.02.2010 № 67, в извещении о проведении аукциона, помимо общих сведений об организаторе аукциона и технических характеристиках имущества, находящегося в государственной или муниципальной собственности, в обязательном порядке должна быть указана начальная, она же и минимальная цена договора (лота), и при необходимости указывается начальная (минимальная) цена лота за единицу площади имущества, сдаваемого в аренду, равная ежемесячному или ежегодному платежу за право пользования и владения указанным имуществом [2].

Далее посмотрим, что декларирует Земельный Кодекс РФ в отношении сдаваемого в аренду земельного участка, находящегося в государственной и муниципальной собственности.

Согласно ст. 39.6 Федерального закона от 23.06.2014 № 171-Ф3 «О внесении изменений в Земельный кодекс Российской Федерации и отдельные законодательные акты Российской Федерации», арендное соглашение по земельному участку, являющемуся государственной или муниципальной собственностью, заключается по результатам торгов, которые проводятся в форме аукциона, с участником, предложившим наибольшую цену, за исключением следующих случаев:

1) если земельный участок предоставляется какому-либо юридическому лицу на основании указа или распоряжения Президента Российской Федерации;

2) если земельный участок предоставляется юридическим лицам на основании распоряжения Правительства Российской Федерации в целях размещения на нем социально-культурных объектов, а таюже на условиях, соответствующих установленным Правительством РФ критериям, реализации инвестиционных проектов [3]. 
Далее необходимо установить, что подразумевается под начальной ценой предмета аукциона на право заключения договора аренды земельного участка, находящегося в государственной или муниципальной собственности, для того чтобы иметь возможность четко сформулировать объект оценки.

После введения изменений в ЗК РФ введена Статья 39.11. Ею установлено, что начальная цена предмета аукциона на право заключения договора аренды земли выбирается и утверждается продавцом по двум вариантам. В качестве первого варианта может выступать годовая величина арендной платы, определенная по результатам рыночной оценки в соответствии с требованиями законодательства в области оценочной деятельности в Российской Федерации, в качестве второго - величина, составляющая полтора процента и выше от кадастровой стоимости такого земельного участка, в случае утверждения результатов государственной кадастровой оценки не ранее чем за пять лет до даты принятия решения о проведении аукциона, за исключением определенных случаев [4]. Такими исключениями являются приобретение данного права на земельный участок, выделенный для комплексного освоения территории или под дачу. В таких исключительных случаях в качестве начальной цены предмета аукциона на право заключения договора аренды выступает величина в размере первого арендного платежа, определенного в отчете об оценке в соответствии с требованиями законодательства в области оценочной деятельности [5].

Таким образом, теперь поправками в ЗК РФ было введено понятие «первый арендный платеж» ст. 39.11.

Итак, с точки зрения релевантности, учитывая современные нормы права, оценщику, при проведении оценки в целях передачи государственного (муниципального) имущества в аренду, требуется знать и понимать, как оценивается первый арендный платеж, он же величина арендной платы за один платежный период, а точнее за первый платежный период. Оценщику, во-первых, необходимо понимать, что фактически оценке подлежит рыночная величина арендной ставки. Следующий аспект, который оценщиком должен быть принят во внимание, это то, что де-юре арендная ставка сама по себе не может являться объектом оценки - в оценочном законодательстве нет такого вида объекта оценки. Если отчет об оценке такого плана будет подвергаться экспертизе на соблюдение закона и стандартов в оценочной деятельности, то учитывая нарушение нормы законодательства, отчет будет признан не соответствующим данным нормам законодательства.

В самом начале мы уже отметили, что в таких случаях не рекомендуем формулировать в отчете объект оценки как «право временного пользования и владения, или пользования на условиях аренды». Причина этого также была разобрана выше. Наиболее правильный вариант остается один, хоть он и не нравится оценщикам, в силу проведения дополнительных расчетов - это «определение рыночной стоимости актива с указанием величины рыночной арендной платы» (годовой или месячной) (п. 9 ФСО № 7 дает возможность такой формулировки). Формулируя объект оценки в таком виде, мы не нарушаем нормы оценочного законодательства, а также это дает возможность экономически верно произвести расчет.

Стоит отметить, что актуальность расчета права аренды остается на вторичном рынке аренды, когда арендатор продает свое право другому лицу. В этой связи актуально будет разобрать некоторые «подводные камни», с которыми оценщик может столкнуться при расчете арендной ставки и права аренды за определенный период.

2. Особенности оценки прав владения и пользования или только пользования на условиях договора аренды.

Итак, у арендатора при передаче ему вещи в аренду появляется право пользования или владения и пользования данной вещью только на определенных условиях, отраженных в договоре аренды. Исходя из этого выгоды у титульного собственника и арендатора от владения и пользования 
одной и той же вещью разные, а значит стоимость права владения и пользования у собственника и арендатора разные. Другими словами, временное право владения и пользования данной вещью у арендатора будет трактоваться как право аренды, которое будет оцениваться арендатором с точки зрения его полезности (интереса), а не полезности (интереса) собственника.

Таким образом, для более точного понимания состава права аренды при проведении его оценки, можно дать следуюшую трактовку рыночной стоимости права аренда. Рыночной стоимостью права аренды объекта аренды можно считать стоимость, которая отражает ожидаемую величину выгоды (дохода) арендатора от права владения и пользования в течение определенного периода времени с учетом наиболее эффективного использования арендатором объекта аренды, а также с учетом всех формальных и фактических обременений права аренды, предусмотренных как законодательством, так и арендным соглашением.

В оценочной практике не всегда оценщики понимают и учитывают разницу между понятиями «арендная ставка», «арендный платеж» и «право аренды». Ранее мы пояснили свою позицию о тождественности понятий арендного платежа и арендной ставки. С точки зрения формирования выгод, а значит и формирования стоимости права аренды, существенное значение имеет разница между договорной и рыночной арендной платой. Договорная арендная плата для арендатора - это его расход. Рыночная арендная плата может являться для него доходом в случае, если он решит продать данное право. Однако, даже если арендатор не продает своего права на рынке и при условии, что договорная арендная ставка меньше рыночной, он все равно получает выгоду в виде экономии. Таким образом, данная экономия порождает экономические выгоды, которые с точки зрения оценки и будут формировать стоимость права аренды. Если по условиям договора аренды арендатор не имеет права сдавать актив в субаренду, а такая экономия и есть экономическая выгода, то право аренды также будет иметь положительную величину. Однако на рынке, безусловно, есть случаи, когда полезность такого права отсутствует: например, если размер арендной платы, установленной договором аренды, выше рыночного размера арендной платы за этот объект. В такой ситуации расчетная величина стоимости права аренды может выражаться отрицательной величиной. Другими словами, если договорные ставки аренды соответствуют рыночным ставкам, то стоимость права пользования на условиях аренды, то есть выгода арендатора, стремится к нулю.

Разберем отдельные методические аспекты оценки права аренды на примере аренды земельного участка как самого частого актива, предоставляемого государством или муниципалитетом в аренду.

Рыночная стоимость права аренды земельного участка в зависимости от наличия информации на рынке определяется с помощью следующих методов:

- сравнения продаж;

- выделения;

- распределения;

- $\quad$ капитализации ренты;

- остатка;

- предполагаемого использования.

Данные методики расчета приведены в соответствующих методических указаниях, и останавливаться на содержании и условиях их применения не будем. Разберем возможные к применению методические аспекты в рамках некоторых методов.

Что касается сравнительного подхода, а точнее метода сравнения продаж, то вне зависимости от региона оценщик с большей долей вероятности столкнется с неразвитостью рынка права аренды земельных участков. В этой связи в качестве объектов аналогов ввиду большего развития рынка продаж земельных участков обычно берутся продажи аналогичных активов, однако 
на практике существует сложность самим определить коэффициент корректировки стоимости для земельного участка (Ка), предоставляемого в аренду на срок, указанный в договоре аренды или в проекте договора. Как правило, Ка определяется одним из следующих методов:

- метод корреляционно-регрессионного анализа связи между изменением элемента сравнения и изменением цен аналогов (цен единиц измерения аналогов) и определением уравнения связи между значением элемента сравнения и величиной рыночной стоимости земельного участка;

- $\quad$ метод парных продаж;

- метод экспертного обоснования корректировок (коэффициентов) (в том числе на основе справочников, аналитических статей, опубликованных в авторитетных изданиях, методических и нормативных положений органов местного самоуправления)

Метод корреляционно-регрессионного анализа связи между изменением элемента сравнения и изменением цен аналогов является громоздким и на практике, как правило, не используется. Применение метода парных продаж мы также видим затруднительным, ввиду того что достаточно трудно подобрать сопоставимые по всем критериям оценки, кроме одного, объекты парных продаж. В этом случае в качестве альтернативы можно применить так называемый «метод скорректированных продаж», когда, прежде чем найти разницу по одному критерию, вводим корректировки на остальные различия в ценообразующих факторах.

Метод экспертного обоснования корректировок основан на мнении экспертов, являющихся специалистами в области рынка недвижимости. Данный метод предполагает количественную оценку корректировок, которая может быть выражена посредством расчета средневзвешенной величины корректировки посредством градации мнений экспертов. В случае использования метода экспертных оценок при расчете Ка, необходимо не забывать в соответствии с п. 13 ФСО № 3 проверять полученные результаты на соответствие рынку.

Далее разберем отдельные особенности определения рыночной величины арендной ставки.

Для начала выделим специфику учета факторов при расчете арендной платы (ставки) при расчете дохода от права аренды и арендной платы при расчете арендного платежа для объекта недвижимости (таб̆л. 1).

Таблица 1

Отличие учета существенных факторов для определения арендной ставки при расчете права аренды и арендного платежа

\begin{tabular}{|l|l|}
\hline \multicolumn{2}{|c|}{ Существенные факторы для определения арендной ставки } \\
\hline \multicolumn{1}{|c|}{ при расчете права аренды } & \multicolumn{1}{|c|}{ при расчете арендного платежа } \\
\hline Срок действия & - \\
\hline $\begin{array}{l}\text { Наличие /отсутствие НДС в определяемой ставке } \\
\text { арендной платы }\end{array}$ & $\begin{array}{l}\text { Наличие /отсутствие НДС в определяемой ставке } \\
\text { арендной платы }\end{array}$ \\
\hline $\begin{array}{l}\text { Сторона, оплачивающая коммунальные услуги и } \\
\text { прочие затраты (например проведение ремонтов, в } \\
\text { том числе незапланированных }\end{array}$ & $\begin{array}{l}\text { Сторона, оплачивающая коммунальные услуги и } \\
\text { прочие затраты (например проведение ремонтов, в } \\
\text { том числе незапланированных }\end{array}$ \\
\hline $\begin{array}{l}\text { Механизм изменения величины ставки арендной } \\
\text { платы }\end{array}$ & - \\
\hline Механизм расторжения договора & - \\
\hline
\end{tabular}

Отметим еше раз, что, по нашему мнению, возможность сдачи актива в субаренду не является существенным фактором ни при расчете права аренды, ни при расчете арендной платы.

Если со сроком, НДС и составом арендной ставки на предмет включения или отсутствия в ней коммунальных затрат все понятно, то по остальным дадим пояснение. Разъясним по поводу существенности механизма изменения величины ставки арендной платы для расчета права 
аренды и несущественности этого фактора для расчета арендного платежа. При оценке права аренды доходным подходом мы можем использовать данную информацию для прогноза денежных потоков с целью дальнейшего их дисконтирования, то есть приведения этих потоков в текущую величину, равную стоимости права аренды. При определении первого арендного платежа оценщик определяет ставку аренды на текущую дату без учета прогнозов и ее дальнейшего изменения. Механизм расторжения договора имеет смысл учитывать также только при расчете права аренды, потому как денежные потоки формируются в течение действия договора аренды, а механизм или порядок расторжения может повлиять на их величину. Если заказчик не предоставил договора аренды или его проекта, необходимо об этом написать в допущениях и производить оценку уже с учетом допущения, которое будет заключаться в том, что оценка производится для стандартных, типичных условий аренды (например, по сроку - это, как правило, 11 мес., возможность сдачи в субаренду и пр. условия).

Рыночная ставка арендной платы подлежит оценке методами трех подходов.

Определение рыночной ставки арендной платы сравнительным подходом, как правило, не вызывает затруднений при развитом рынке арендной платы в соответствующем сегменте рынка. Здесь количество ценообразующих факторов, учитываемых при оценке методом сравнения продаж, ненамного отличается от учета факторов при определении рыночной стоимости тем же методом самого актива. При расчете арендной ставки необходимо учитывать те значимые факторы, которые вытекают из договора аренды (см. табл.2).

В доходном подходе при расчете ставки аренды в теории оценки предлагается использовать метод добавочной продуктивности. В рамках данного метода производится расчет годового дохода от предпринимательской деятельности типичного арендатора, который затем распределяется между факторами производства, участвующими в формировании прибыли от бизнеса. Затем вычитается сумма дохода, «генерируемая» недвижимостью, и определяется "добавочная продуктивность» земли и улучшений по принципу остатка. Использование данного метода на практике реализовать достаточно непросто, ввиду того что расчет доли того или иного фактора производства, которую он внес в формирование дохода, вызовет потребность в запросе у заказчика большого количества информации, содержащейся в финансовой и технической документации. Ее не всегда заказчик готов обнародовать, а для оценщика объем трудозатрат будет сопоставим с оценкой бизнеса, а не земельным участком.

В затратном подходе оценщики обычно используют «метод компенсации издержек доходами». Экономический смысл этого метода заключается в том, что арендодатель устанавливает такую арендную плату, при которой он мог бы не только обеспечить возврат капитала, но и получить доход на вложенный капитал.

На первом шаге реализации данного метода при определении рыночной стоимости самого актива сравнительным или доходным подходом проблем при развитом сегменте рынка, к которому принадлежит объекта оценки, как правило, не возникает у оценщиков.

А вот на втором шаге, когда оценщику приходится решать «обратную задачу» теории оценки недвижимости и «рекапитализировать» полученную на первом этапе стоимость в потенциальный валовой доход с использованием рыночного коэффициента капитализации, необходимо обращать внимание на ряд нюансов. Заметим, что при обратной капитализации стоимости актива получается чистый операционный доход (ЧОД), к которому добавляются, помимо операционных расходов, ожидаемые потери, недозагрузка и неплатежи. При выборе величины недозагрузки для объекта недвижимости следует учитывать следующие факторы:

- обеспеченность потребителей территории подобными объектами недвижимости, количество подобных предложений;

- наличие свободных площадей подобного типа и подобного уровня в ближайшем окружении; 
- наличие / отсутствие каких-либо дополнительных удобств;

- площадь объекта и его объемно-планировочные показатели.

При выборе величины операционных расходов для объектов недвижимости следует учитывать следующие факторы:

- тип объекта (у встроенных помещений, например затраты, как правило, меньше, также, как у незастроенных земельных участков по сравнению с застроенными);

- физическое состояние недвижимости;

- $\quad$ материал изготовления и специфика объекта (влияют на затраты по страхованию);

- средняя заработная плата специалистов, занимающихся управлением недвижимости, в данном регионе;

- место расположения объекта (охраняемая территория или нет), условия обеспечения охраны объекта;

- организация уборки помещений, наличие договоров с клиринговыми компаниями.

Достаточное количество нюансов возникает и при определении коэффициента капитализации. B оценочной теории и практики определение коэффициента капитализации (R) осуществляется следующими способами:

- делением величины чистого операционного дохода по аналогичным объектам на цену их продажи (метод рыночной экстракции);

- $\quad$ увеличение безрисковой ставки отдачи на капитал на величину премии за риск, связанный с инвестированием капитала в оцениваемый земельный участок (кумулятивная модель построения).

Конечно, при развитом рынке наиболее точным является первый метод - «рыночный метод»:

$$
R=\text { ЧОД } / \text { РС }
$$

Однако, например, при оценке стоимости земельных участков данным методом могут возникать проблемы, связанные с тем, что достаточно развитого рынка свободных земельных участков на сегодняшний день нет (участки, не занятые зданиями, строениями, продаются и сдаются в аренду в меньшем количестве, чем застроенные). Такие сложности есть практически на всех сегментах рынка земли и во всех регионах:

- для сегмента ИЖС характерным является большое количество свободных земельных участков в продаже и практическое отсутствие предложений по аренде;

- для офисно-торговой недвижимости в крупных городах рынок продаж развит, в мелких, как правило, оставляет желать лучшего, а предложения по аренде, если и встречаются, то только при сдаче государственной или муниципальной земли и в ограниченном количестве;

- для земельных участков для производственной застройки, ситуация в каких-то городах чуть лучше, чем на рынке земель под торгово-офисную застройку, а в каких-то ничем не отличается.

Второй способ предполагает добавление различных премий за риск к безрисковой ставке. Достоинством данного метода является то, что он позволяет учесть те риски, которые значимы именно для оцениваемого актива. Недостаток данного метода заключается в том, что во многом он является субъективным, а значит менее точным. Однако зачастую у оценшика не остается выбора, как рассчитывать коэффициент капитализации им. Важный момент: оценщикам необходимо понимать, что данная модель не работает в крупных городах. Там коэффициент капитализации для объектов недвижимости при проверке рыночным методом зачастую показывает меньшие величины, чем безрисковая ставка. Необходимо понимать, что вложения в такого рода активы хозяйствующие субъекты считают самыми безрисковыми. 
Пример. В обосновании этого факта приведем пример расчета ставки капитализации методом рыночной экстракции на примере офисного сегмента рынка в г. Москве - наиболее распространенного одновременно как по сделкам продаж, так и по сделкам аренды (таблица 2).

Таблииа 2

Пример расчета ставки капитализации методом рыночной экстракции на примере офисного сегмента рынка в г. Москве

\begin{tabular}{|c|c|c|c|}
\hline Наименование объекта & $\begin{array}{c}\text { Офисные помещения - } \\
\text { парная продажа № } 1\end{array}$ & $\begin{array}{c}\text { Офисные помещения - } \\
\text { парная продажа № } 2\end{array}$ & $\begin{array}{c}\text { Офисные помещения - } \\
\text { парная продажа № } 3\end{array}$ \\
\hline Местоположение & Дмитровское шा., 71Б & $\begin{array}{c}\text { ул. Сущёвский Вал, } \\
\text { Д. } 49, \text { стр. } 2\end{array}$ & пр-т Мира \\
\hline Класс здания & $\mathrm{B}$ & $\mathrm{B}$ & B \\
\hline Тип отделки & класс «Люкс» & класс «Люкс» & класс «Люкс» \\
\hline $\begin{array}{l}\text { Стоимость } \\
\text { предложения, р./м. кв }\end{array}$ & 180000 & 190881 & 302842 \\
\hline $\begin{array}{l}\text { Ставка аренды, } \\
\text { р./кв. м/год }\end{array}$ & 18900 & 20989 & 30000 \\
\hline Недозагрузка, \% от ПВД & 12,6 & 12,6 & 12,6 \\
\hline $\begin{array}{l}\text { Операционные расходы, } \\
\text { \% от ПВД }\end{array}$ & 17,8 & 17,8 & 17,8 \\
\hline ЧОД, p./кв. м & 13154 & 14608 & 20880 \\
\hline $\begin{array}{l}\text { Рыночная стоимость, } \\
\text { p./ кв. м }\end{array}$ & 180000 & 190881 & 302842 \\
\hline $\begin{array}{l}\text { Коэффициент } \\
\text { капитализации, \% }\end{array}$ & 7,3 & 7,65 & 6,89 \\
\hline
\end{tabular}

Недозагрузка, операционные расходы определялись по данным Справочника оценщика недвижимости - офисно-торговая недвижимость и сходные типы объектов (4-е ид., актуализированное и расширенное / под ред. Л. А. Лейфера. - Нижний Новгород: ЗАО (ПЦФКО», 2016) как среднее значение. По ключевым ценообразующим параметрам (класс здания, местоположение, тип отделки) у объектов в рамках парной продажи различий нет, поэтому корректирующие коэффициенты не применялись.

Таким образом, среднее значение коэффициента капитализации составит 7,28 \%, что, несомненно, ниже безрисковой ставки, определяемой типичным способом по средней доходности государственных облигаций либо по результатам анализа финансового рынка. Схожая ситуация и на рынке жилой недвижимости. По данным проведенного нами анализа жилого сегмента, как также наиболее развитого одновременно и по рынку продаж и по рынку аренды, коэффициент капитализации методом рыночной экстракции получился менее 6 \%. Таким образом, данный пример наглядно показал нам, что ситуации в крупных городах не являются типовыми, и применять стандартные подходы в определении ставки капитализации оценщикам не следует (в первую очередь мы имеем ввиду метод кумулятивного построения). С нашей точки зрения, вложения в государственные ценные бумаги не являются альтернативой инвестиций в объекты недвижимости, расположенные в исторических центрах городов или просто в крупных городах, поскольку такая недвижимость является наиболее безрисковым ликвидным активом, существующим в нашей стране

Что в такой ситуации можно сделать? Вполне решаемым способом для определения, например, ставки капитализации для земли может выступать - назовем его «способ расчета с учетом взвешенной). 


$$
R_{3 y}=R_{E O H} \cdot W_{3 y},
$$

где $R_{E O H}$ - коэффициент капитализации от единого об́ъекта недвижимости, рассчитанный методом рыночной экстракции; $W_{3 y}$ - доля стоимости земельного участка в стоимости об́ъекта недвижимости.

Необходимо отметить, что проблем расчета ставки капитализации для единого объекта методом рыночной экстракции гораздо меньше, ввиду достаточно развитого рынка аренды единых объектов недвижимости, как правило, по всем городам. Кроме того, долю стоимости земельного участка также несложно определить, используя информацию о средних ценах единого объекта на соответствующем сегменте рынка и ценах на свободные земельные участки, тем более что анализ диапазона цен оценщик обязан проводить в рамках отчета об оценке. Методики определения типовой доли земельного участка приведены в различных работах, из которых укажем, например статью [6], в которой приведены ссылки и на наиболее ранние публикации.

Учитывая, что в соответствии с рассмотренными аналитическими работами, в которых выведен удельный вес стоимости земли в стоимости единого объекта недвижимости, среднее значение доли земельного участка существенно мало и колеблется от 17 до $37 \%$ в зависимости от его разрешенного использования [6].

Безусловно, данный способ будет являться альтернативой двум рассмотренным выше методам только при невозможности рассчитать коэффициент капитализации ими.

Заключение /Conclusion. Использование в практике оценки сформулированных определений и обоснованных доводов относительно юридической и экономической составляющей права пользования на условиях аренды позволит правильно формулировать объект оценки и выбирать верную методологию, в частности при проведении оценки права на заключение договора аренды объектов недвижимости, находящихся в государственной или муниципальной собственности.

\section{ЛИТЕРАТУРА И ИНТЕРНЕТ-РЕСУРСЫ}

1. Гражданский кодекс Российской Федерации (часть вторая): Федеральный закон от 30 ноября 1994 года № 51-ФЗ. - Текст : непосредственный.

2. О порядке проведения конкурсов или аукционов на право заключения договоров аренды, договоров безвозмездного пользования, договоров доверительного управления имуществом, иных договоров, предусматривающих переход прав в отношении государственного или муниципального имущества, и перечне видов имущества, в отношении которого заключение указанных договоров может осуществляться путем проведения торгов в форме конкурса : Приказ ФАС России от 10.02.2010 № 67. Текст : непосредственный.

3. О внесении изменений в Земельный кодекс Российской Федерации и отдельные законодательные акты Российской Федерации : Федеральный закон от 23.06.2014 № 171-Ф3. - Текст : непосредственный.

4. Земельный кодекс Российской Федерации : Федеральный закон от 25 октября 2001 года № 136-Ф3. Текст : непосредственный.

5. Ларионов, А. Н. К вопросу о роли законодательства Российской Федерации в обеспечении комплексного освоения территорий для жилищного строительства / А. Н. Ларионов, О. В. Дмитриева // Имущественные отношения в Российской Федерации. - 2017. - № 4. - С. 81-85. - Текст : непосредственный.

6. Сутягин, В. Ю. Методическое обеспечение оценки застроенных участков / В. Ю. Сутягин, Р. Ю. Черкашнев // Социально-экономические явления и процессы. - 2012. - № 12. - С. 296-311. - Текст : непосредственный.

\section{REFERENCES AND INTERNET RESOURCES}

1. Grazhdanskij kodeks Rossijskoj Federacii (chast'vtoraya): Federal'nyj zakon ot 30 noyabrya 1994 goda № 51-FZ (Civil Code of the Russian Federation (Part Two): Federal Law No. 51-FZ of 30 November 1994).

2. O poryadke provedeniya konkursov ili aukcionov na pravo zaklyucheniya dogovorov arendy, dogovorov bezvozmezdnogo pol'zovaniya, dogovorov doveritel'nogo upravleniya imushchestvom, inyh dogovorov, predusmatrivayushchih perekhod prav v otnoshenii gosudarstvennogo ili municipal'nogo imushchestva, 
i perechne vidov imushchestva, $\mathrm{v}$ otnoshenii kotorogo zaklyuchenie ukazannyh dogovorov mozhet osushchestvlyat'sya putem provedeniya torgov v forme konkursa : Prikaz FAS Rossii ot 10.02.2010 № 67 (About an order of holding competitions or auctions on the right of signing of the contracts of rent, contracts of free use, contracts of trust management of property, other contracts providing transition of the rights concerning the state or municipal property, and the list of types of property concerning which the conclusion of the specified contracts can be carried out by tendering in the form of a competition: Order of FAS Russia of 10.02.2010 N 67).

3. O vnesenii izmenenij v Zemel'nyj kodeks Rossijskoj Federacii i otdel'nye zakonodatel'nye akty Rossijskoj Federacii : Federal'nyj zakon ot 23.06.2014 № 171-FZ (On Amendments to the Land Code of the Russian Federation and Certain Legislative Acts of the Russian Federation: Federal Law of 23.06.2014 N 171-Ф3).

4. Zemel'nyj kodeks Rossijskoj Federacii : Federal'nyj zakon of 25 oktyabrya 2001 goda № 136-FZ (Federal Law No. 136-Ф3 of 25 October 2001).

5. Larionov, A. N. K voprosu o roli zakonodatel'stva Rossijskoj Federacii v obespechenii kompleksnogo osvoeniya territorij dlya zhilishchnogo stroitel'stva (To the issue of the role of the legislation of the Russian Federation in ensuring the comprehensive development of territories for housing construction) / A. N. Larionov, O. V. Dmitrieva // Imushchestvennye otnosheniya v Rossijskoj Federacii. - 2017. № 4. - S. 81-85.

6. Sutyagin, V. YU. Metodicheskoe obespechenie ocenki zastroennyh uchastkov (Methodological support of assessment of built-up sites) / V. YU. Sutyagin, R. YU. CHerkashnev // Social'no-ekonomicheskie yavleniya i processy. -2012 . - № 12. - S. 296-311.

\section{СВЕДЕНИЯ ОБ АВТОРАХ}

Чернышова Оксана Николаевна, кандидат экономических наук, доцент, доцент кафедры «Финансы и банковское дело», Тамбовский государственный университет им. Г.Р. Державина, г. Тамбов; эксперт по оценке имущества, член Экспертного совета некоммерческого партнерства «Саморегулируемая организация «СВОД». E-mail: optmb@yandex.ru

Сутягин Владислав Юрьевич, кандидат экономических наук, доцент, доцент кафедры «Финансы и банковское дело», Тамбовский государственный университет им. Г.Р. Державина, г. Тамбов; эксперт по оценке имущества, член Экспертного совета некоммерческого партнерства «Саморегулируемая организация «СВОД». E-mail: vl.sutyagin 0 gmail.com

Черкашнев Роман Юрьевич, кандидат экономических наук, доцент, доцент кафедры «Финансы и банковское дело», Тамбовский государственный университет им. Г.Р. Державина, г. Тамбов. E-mail: zakat05@mail.ru

\section{INFORMATION ABOUT AUTHORS}

Chernyshova Oxana Nikolayevna, Candidate of Economic Sciences, associate professor, associate professor «Finance and banking», Tambov state university of G.R. Derzhavin, Tambov, expert in assessment of property, member of Advisory council of SVOD self-regulatory organization non-profit partnership. E-mail: optmb@yandex.ru

Sutyagin Vladislav Yurevich, Candidate of Economic Sciences, associate professor, associate professor «Finance and banking», Tambov state university of G.R. Derzhavin, Tambov, expert in assessment of property, member of Advisory council of SVOD self-regulatory organization non-profit partnership. E-mail: vl.sutyaginagmail.com

Chernashnev Roman Yurevich, Candidate of Economic Sciences, associate professor, associate professor «Finance and banking», Tambov state university of G.R. Derzhavin, Tambov. E-mail: zakat05@mail.ru 